\title{
Active Tuned Mass Dampers for Control of Seismic Structures
}

\author{
AYLIN ECE KAYABEKİR \\ Department of Civil Engineering \\ Istanbul University-Cerrahpaşa \\ 34320 Avc1lar, Faculty of Engineering, Istanbul, Turkey \\ TURKEY \\ SINAN MELİH NİGDELİ \\ Department of Civil Engineering \\ Istanbul University-Cerrahpaşa \\ 34320 Avc1lar, Faculty of Engineering, Istanbul, Turkey \\ TURKEY \\ GEBRAİL BEKDAŞ \\ Department of Civil Engineering \\ Istanbul University-Cerrahpaşa \\ 34320 Avc1lar, Faculty of Engineering, Istanbul, Turkey \\ TURKEY
}

\begin{abstract}
Structural control has been implemented to major structures that are exposed to excitations which have random vibration behavior including strong winds, traffics and especially ground accelerations resulting from strong earthquakes. It is possible to apply passive and active control methods. In passive, structures are controlled via additional mechanical components, while and external force generating by a powered motor is needed for active control. In the practice of this study, active tuned mass dampers (ATMDs) are used to reduce vibration and responses of structures. The parameters of Proportional-Integral-Derivative (PID) type controllers used in ATMD was found via trial-error method, while mechanical properties of mass damper are optimized via metaheuristic algorithm called Jaya Algorithm. The results were compared with passive tuned mass damper (TMD) and uncontrolled structure. The tuned ATMD is effective to reduce structural vibrations better than TMD. In future studies, both mechanical and controller parameters can be optimized via metaheuristic algorithms.
\end{abstract}

Key-Words: Active Tuned Mass Dampers, Structural Control, Optimization, Metaheuristic.

Received: December 8, 2019. Revised: March 30, 2020. Accepted: May 2, 2020. Published: May 14, 2020.

\section{Introduction}

Structural control systems that are used for damping energy due to external loads such as earthquake or wind, are generally classified under two headings as active and passive. In general, passive control systems are based on the principle of providing energy distribution between the building and the system without the need an external energy source and as a result, a significant part of the energy is consumed by control system. Active control systems, on the other hand, damp the structural reactions by applying time-varying forces, and thus ensure the structure to be rapidly stabilized even in the face of high-impact dynamic effects. However, large energy sources may be needed to generate these control forces.
Active tuned mass dampers (ATMDs), a type of active control, can be defined as a system derived by adding an active control mechanism including sensor, controller and actuator to the tuned mass dampers (TMD) to increase the applicability of the TMD systems at variable frequencies. According to principle of ATMD, after real-time data obtained by sensors are evaluated, appropriate force is applied to the structure via actuators. Because these control forces are calculated according to the control algorithms pre-defined to the controller or control computer, control algorithms have a big role in the structural control systems.

Some of these algorithms are sliding mode control (SMC), linear quadratic regulator (LQR), linear quadratic Gaussian (LQG), fuzzy logic controller

(FLC) and 
Proportion+Integral+Derivative type controllers (PID). Examples of these studies on structural control are: [1], [2] (SMC); [3], [4] (LQR); [5], [6], [7] (LQG and FLC); [8], [9] (FLC), [10] (FLC and PD); [11]; [12] (fuzzy PID controller), [13] (PID and LQR).

In this study, using optimum TMD parameters obtained by optimization based on metaheuristic algorithm, ATMD parameters including PID control algorithm parameters are searched by trial and error. Then, the effectiveness of the TMD and ATMD systems is compared with the uncontrolled structure. As a result of comparative analysis, it is concluded that both TMD and ATMD are effective in reducing structural responses, but ATMD is more effective in reducing relative displacements.

\section{The equations for structures with ATMD}

A shear building with an ATMD on the top is shown as Figure 1. In the figure, the story properties of structures are shown as $\mathrm{m}_{\mathrm{i}}, \mathrm{k}_{\mathrm{i}}$ and $\mathrm{c}_{\mathrm{i}}$ for mass, stiffness, damping coefficient of $i^{\text {th }}$ story, respectively. The ATMD parameters are $m_{d}, k_{d}$ and $\mathrm{c}_{\mathrm{d}}$ for mass, stiffness and damping coefficient, respectively. The equation of motion in matrix form is shown as Eq. (1).

$$
M \ddot{\mathrm{x}}(\mathrm{t})+C \dot{\mathrm{x}}(\mathrm{t})+K \mathrm{x}(\mathrm{t})=-M\{I\} \ddot{\mathrm{x}}_{\mathrm{g}}(\mathrm{t})+\mathrm{F}
$$

In the Eq. (1), M, K and $\mathrm{C}$ are the mass, stiffness and damping matrices of the structure with ATMD, respectively. $\ddot{x}_{\mathrm{g}}$ is ground acceleration resulting from earthquake and $\{1\}$ is a vector of ones with dimension $(\mathrm{N}+1) \times 1$ for a $\mathrm{N}$-story structure with a ATMD on top.

The matrices in Eq. (1) and the displacement vector $(x(t))$ are shown in Eqs. (2)-(5).

$\mathrm{M}=\operatorname{diag}\left[\begin{array}{llll}m_{1} & m_{2} & \ldots & m_{N} m_{d}\end{array}\right]$

$$
\mathrm{C}=\left[\begin{array}{cccccc}
\left(\mathrm{c}_{1}+\mathrm{c}_{2}\right) & -\mathrm{c}_{2} & & & & \\
-\mathrm{c}_{2} & \left(\mathrm{c}_{2}+\mathrm{c}_{3}\right) & -\mathrm{c}_{3} & & & \\
& \cdot & \cdot & & & \\
& \cdot & \cdot & \cdot & & \\
& & \cdot & \cdot & \cdot & \\
& & & -c_{N} & \left(c_{N}+c_{d}\right) & -c_{d} \\
& & & & -c_{d} & c_{d}
\end{array}\right]
$$

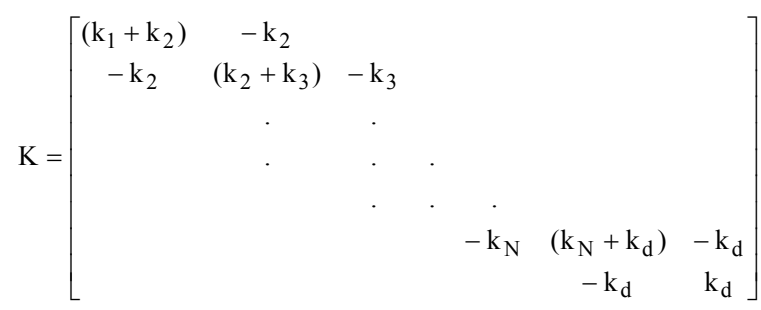

$$
x(t)=\left\{\begin{array}{l}
x_{1} \\
x_{2} \\
\vdots \\
x_{N} \\
x_{d}
\end{array}\right\}
$$

$\mathrm{F}$ is the force vector applied from the actuators driven by controllers. It is given as Eq. (6).

$$
\mathrm{F}(t)=\left\{\begin{array}{l}
0 \\
0 \\
\vdots \\
F_{u} \\
-F_{u}
\end{array}\right\}
$$

$F_{u}$ is the control force, and it is applied to ATMD and the story where ATMD is attached. The control force is found according to Eq. (7), where $\mathrm{K}_{\mathrm{f}}$ is the thrust constant, and $i_{\text {ATMD }}$ is the current of armature coil.

$\mathrm{F}_{\mathrm{u}}=\mathrm{K}_{\mathrm{f}} \mathrm{i}_{\mathrm{ATMD}}$

The control voltage on the control signal produced by the controller $(u)$ is used to find $i_{\text {ATMD }}$ as given Eq. (8). $R$ and $K_{e}$ are the resistance value and induced voltage constant of the armature coil, respectively. According to the velocity of ATMD $\left(\dot{x}_{\mathrm{d}}\right)$, the stroke of ATMD is also considered in Eq. (8).

$$
\mathrm{Ri}_{\mathrm{ATMD}}+\mathrm{K}_{\mathrm{e}}\left(\dot{\mathrm{x}}_{\mathrm{d}}-\dot{\mathrm{x}}_{\mathrm{N}}\right)=\mathrm{u}
$$

The control signal $(\mathrm{u})$ is generated from the controller according to a control algorithm. In the present study, Proportional-Integral-Derivative (PID) type controllers are used. The equation of PID controller is given as Eq. (9).

$u=K_{p}\left[e(t)+T_{d} \frac{d e(t)}{d t}+\frac{1}{T_{i}} \int e(t) d t\right]$ 


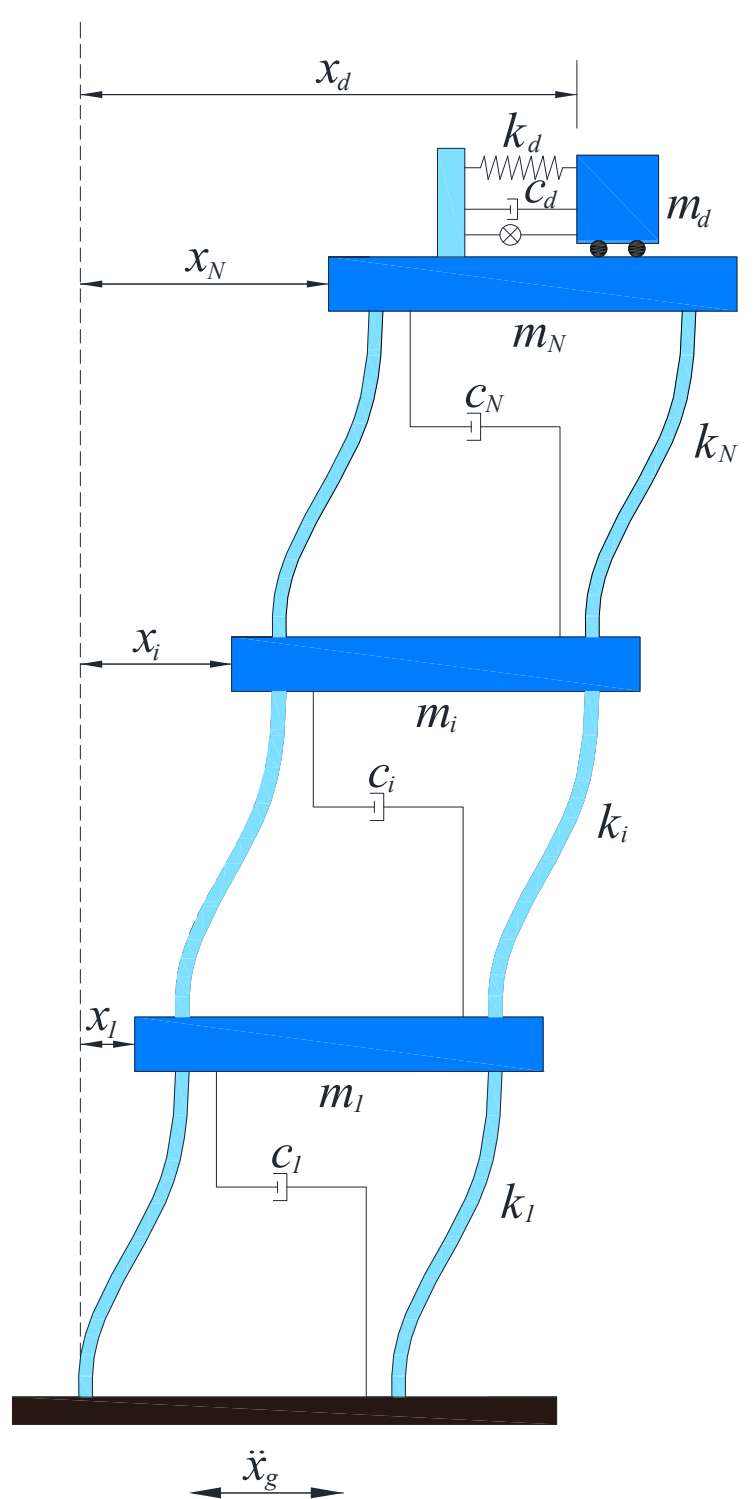

Fig. 1. A structural model with ATMD on the top.

The PID controller parameters, which are tuned according to trial and error method, are namely proportional gain $\left(\mathrm{K}_{\mathrm{p}}\right)$, derivative time $\left(\mathrm{T}_{\mathrm{d}}\right)$ and integral time $\left(\mathrm{T}_{\mathrm{i}}\right)$. e $(\mathrm{t})$ is the error signal which is wanted to be eliminated. In the present study, the error signal is taken as the top story velocity of the structure. In that case, velocity feedback control is done.

\section{The optimization methodology}

For the best performance of TMDs for seismic structures, the parameters are needed to optimally tuned. Since the nonlinear and complex nature of the problem, it is not suitable to use mathematical methods in optimization. Due to that, the use of metaheuristic method is the recent trend in this subject. The metaheuristic algorithms use a metaphor for the inspiration, and several algorithms such as genetic algorithm [14-17], particle swarm optimization [18-19], harmony search [20-22], ant colony optimization [23], artificial bee colony optimization [24], teaching learning based optimization [25] and flower pollination algorithm [26] have been employed for the design of TMDs.

The parameters such as stiffness $\left(\mathrm{T}_{\mathrm{d}}\right)$ (Eq. (10)) and damping coefficient $\left(\zeta_{\mathrm{d}}\right)$ (Eq.(11)) of ATMD are optimized via Jaya Algorithm (JA). This method can be also used to optimize passive TMDs.

$$
\mathrm{T}_{\mathrm{d}}=2 \pi \sqrt{\frac{\mathrm{m}_{\mathrm{d}}}{\mathrm{k}_{\mathrm{d}}}}
$$

$$
\xi_{\mathrm{d}}=\frac{\mathrm{c}_{\mathrm{d}}}{2 \mathrm{~m}_{\mathrm{d}} \sqrt{\frac{\mathrm{k}_{\mathrm{d}}}{\mathrm{m}_{\mathrm{d}}}}}
$$

JA is a single-phase metaheuristic algorithm using Eq. (12). The name "JAYA" comes from the Sanskrit word meaning victory [27]. To gain victory by using the optimum solution, the best $\left(\mathrm{g}^{*}\right)$ and worst $\left(\mathrm{g}^{\mathrm{w}}\right)$ existing solutions are used to converge and diverge to optimum result. Two randomly defined numbers between 0 and $1\left(r_{1}\right.$ and $\left.r_{2}\right)$ are used to update the existing solution $\left(\mathrm{x}_{\mathrm{i}}^{\mathrm{t}}\right)$ of $\mathrm{I}^{\text {th }}$ population and $\mathrm{t}^{\text {th }}$ iteration. The new solution $\left(\mathrm{x}_{\mathrm{i}}^{\mathrm{t}+1}\right)$ of the new iteration is saved if the value of the objective function, which is minimization top story displacement under the critical earthquake excitation of set of records.

$x_{i}^{t+1}=x_{i}^{t}+r_{1}\left(g^{*}-\left|x_{i}^{t}\right|\right)-r_{2}\left(g_{w}-\left|x_{i}^{t}\right|\right)$

The problem is constrained with Eq. (13) for the limitation of the stroke of TMD. It must less than a user defined st max value. $\mathrm{x}_{\mathrm{d}}$ and $\mathrm{x}_{\mathrm{N}}$ represent the displacement of TMD and top story of the structure, respectively.

$$
\mathrm{g}_{1}=\frac{\max \left(\left|\mathrm{x}_{\mathrm{d}}-\mathrm{x}_{\mathrm{N}}\right|\right)_{\text {withTMD }}}{\max \left(\left|\mathrm{x}_{\mathrm{N}}\right|\right)_{\text {withoutTMD }}}<\mathrm{st}_{-} \text {max }
$$

The flowchart of the stages of the optimization are summarized in the flowchart given as Fig. 2. 


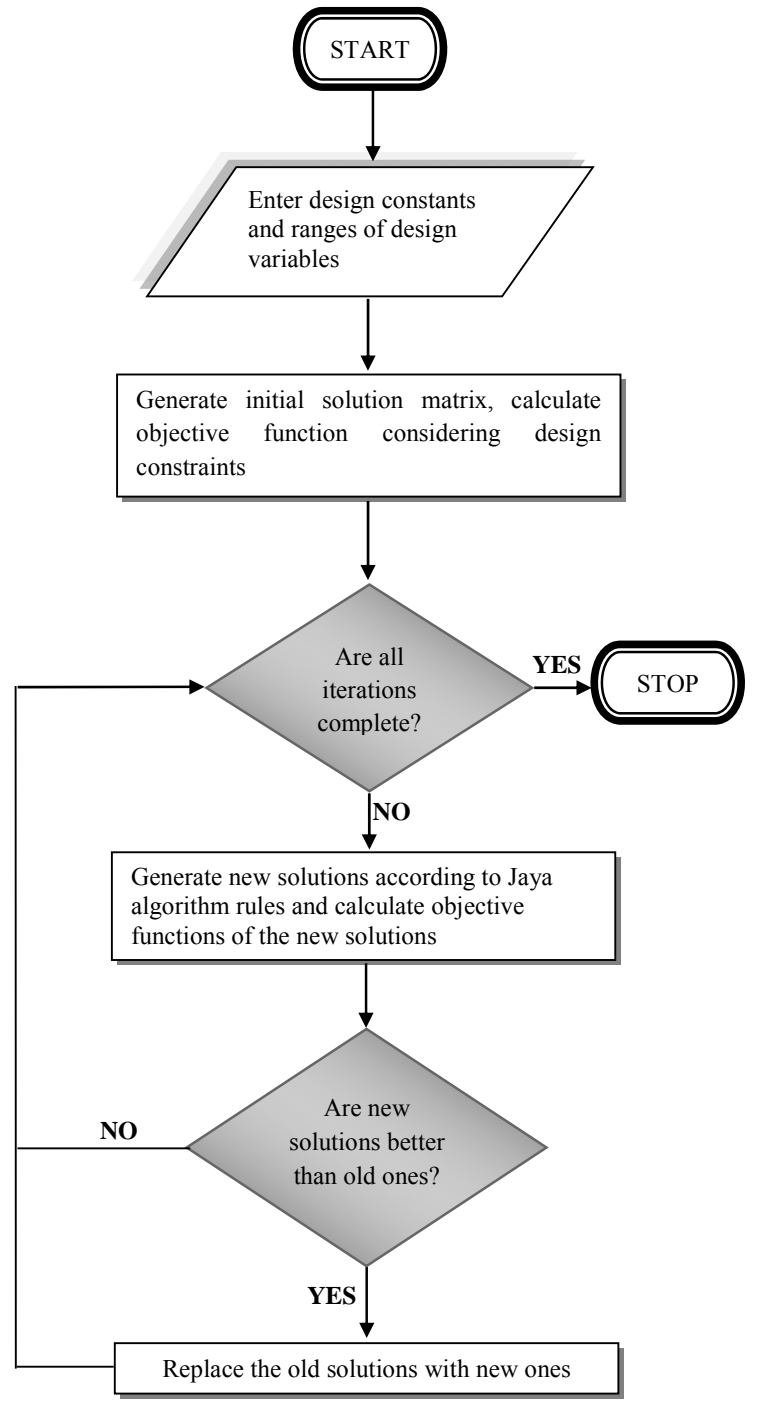

Fig. 2. The flowchart of the optimization process.
A ten-story shear structure model with an ATMD on the top was investigated. The properties such as mass, stiffness and damping coefficients are 360t, $650 \mathrm{MN} / \mathrm{m}$ and $6.2 \mathrm{MNs} / \mathrm{m}$, respectively for each story [16]. The mass of TMD is taken as the $5 \%$ of the total mass of the structure (180t). The optimum stiffness and damping coefficients of TMD are configured according to the optimum period and damping ratio values found as $0.9023 \mathrm{~s}$ and 0.2821 , respectively for st_max $=1$.

The constant parameters in active control are taken as follows: $\mathrm{R}=4.2 \Omega, \mathrm{K}_{\mathrm{f}}=2 \mathrm{~N} / \mathrm{A} ; \mathrm{K}_{\mathrm{e}}=2 \mathrm{~V}$. The tuned PID controller parameters via trials were found as $K_{p}=-3000 \mathrm{Ns} / \mathrm{m}, T_{d}=235 \mathrm{~s} ; T_{\mathrm{i}}=10000 \mathrm{~s}$.

The optimization of TMD was done for set of farfield ground motions presented in FEMA P-695: Quantification of Building Seismic Performance Factors [28]. These records are listed in Table 1. The time history results obtained for BOL090 earthquake record, which is determined to be critical earthquake among 44 different earthquake data, are given in Figure 3 for uncontrolled structure and structures with TMD and ATMD.

According to this, it is shown that when there is no structural control, maximum displacement is 0.4101 $\mathrm{m}$. When the attaching the TMD to structure, this maximum value is decreased to $0.3202 \mathrm{~m}$. However, ATMD provides more effectively reducing to maximum displacement, and this value decreases up to $0.2428 \mathrm{~m}$.

\section{The numerical example}

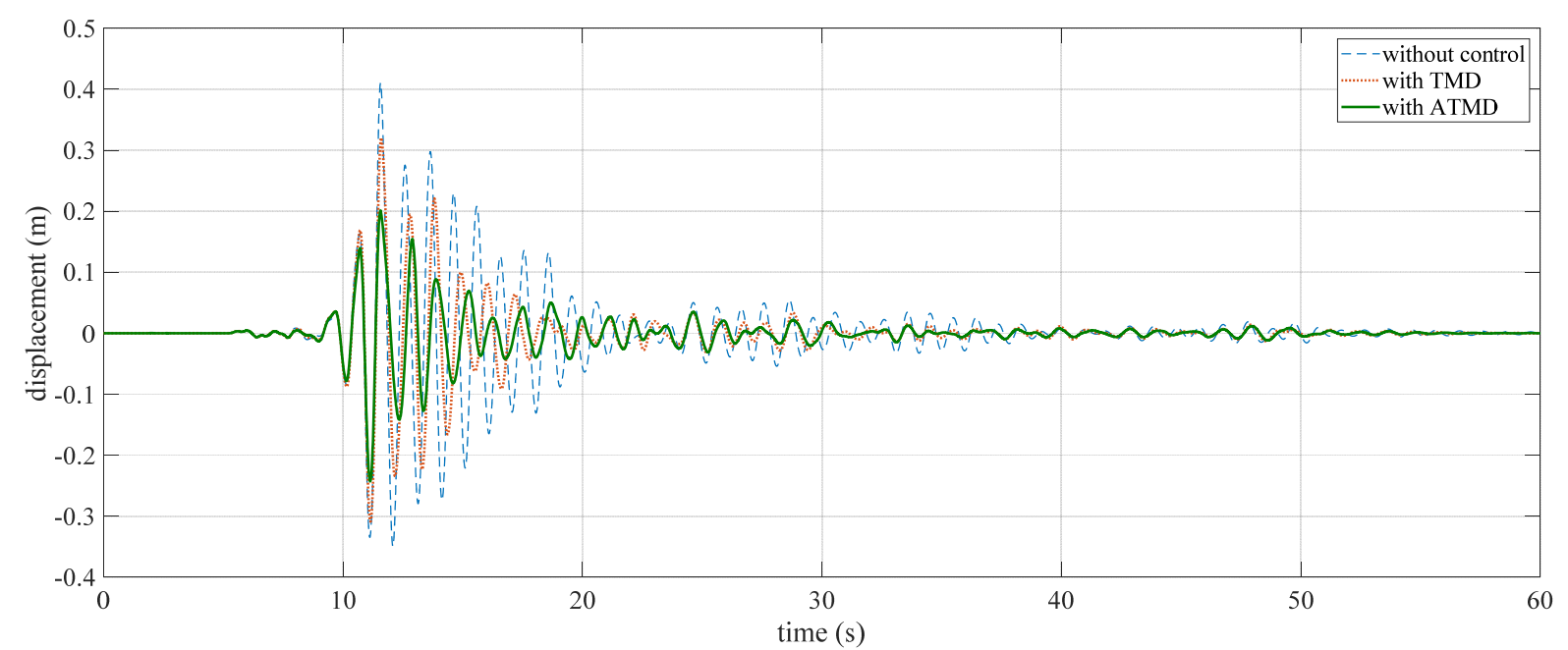

Fig. 3. Time Histories of the structure with and without structural control 
Table 2. FEMA P-695 far-field ground motion records [28]

\begin{tabular}{llll}
\hline Name & Date & Component 1 & Component 2 \\
\hline Northridge & 1994 & NORTHR/MUL009 & NORTHR/MUL279 \\
Northridge & 1994 & NORTHR/LOS000 & NORTHR/LOS270 \\
Duzce, Turkey & 1999 & DUZCE/BOL000 & DUZCE/BOL090 \\
Hector Mine & 1999 & HECTOR/HEC000 & HECTOR/HEC090 \\
Imperial Valley & 1979 & IMPVALL/H-DLT262 & IMPVALL/H-DLT352 \\
Imperial Valley & 1979 & IMPVALL/H-E11140 & IMPVALL/H-E11230 \\
Kobe, Japan & 1995 & KOBE/NIS000 & KOBE/NIS090 \\
Kobe, Japan & 1995 & KOBE/SHI000 & KOBE/SHI090 \\
Kocaeli, Turkey & 1999 & KOCAELI/DZC180 & KOCAELI/DZC270 \\
Kocaeli, Turkey & 1999 & KOCAELI/ARC000 & KOCAELI/ARC090 \\
Landers & 1992 & LANDERS/YER270 & LANDERS/YER360 \\
Landers & 1992 & LANDERS/CLW-LN & LANDERS/CLW-TR \\
Loma Prieta & 1989 & LOMAP/CAP000 & LOMAP/CAP090 \\
Loma Prieta & 1989 & LOMAP/G03000 & LOMAP/G03090 \\
Manjil, Iran & 1990 & MANJIL/ABBAR--L & MANJIL/ABBAR--T \\
Superstition Hills & 1987 & SUPERST/B-ICC000 & SUPERST/B-ICC090 \\
Superstition Hills & 1987 & SUPERST/B-POE270 & SUPERST/B-POE360 \\
Cape Mendocino & 1992 & CAPEMEND/RIO270 & CAPEMEND/RIO360 \\
Chi-Chi, Taiwan & 1999 & CHICHI/CHY101-E & CHICHI/CHY101-N \\
Chi-Chi, Taiwan & 1999 & CHICHI/TCU045-E & CHICHI/TCU045-N \\
San Fernando & 1971 & SFERN/PEL090 & SFERN/PEL180 \\
Friuli, Italy & 1976 & FRIULI/A-TMZ000 & FRIULI/A-TMZ270 \\
\hline
\end{tabular}

\section{Conclusions and future works}

According to the results, ATMD is effective to reduce maximum displacement under the critical excitation by $41 \%$, while a passive TMD reduces the same response by $\% 22$. The reduction of responses by using active control may be more than the reduction values, if the PID controller parameter are also optimized via metaheuristic method.

In the future studies, the PID controller parameters such as $K_{p}, T_{d}$ and $T_{i}$ will be also taken as design variables. There are two options to optimize HTMDs. The first option is to use separate optimization processes for mechanical parameters (period and stiffness of mass damper) and controller parameters. Thus, it may be effective to find and optimum design for a hybrid mass damper which can work as passive without energy and active with energy. The second option is to optimize all parameters in an optimization process, and the most reduction can be provided for ATMD.

The difficulties of applying metaheuristic-based optimization to PID parameters can be summarized as follows; if the optimization is done according time-domain solutions.

- The range of PID controller parameters may be give a physical solution in a high range. This situation may increase the computation time. For that reason, a suitable range can be defined by trials. - The structure with ATMD for several PID parameters may give infinitive results due stability error. This situation interrupts the optimization process. A threshold must be defined to check this situation. 
- Several limits such as control force must be considered as design constraints. For the bets set of PID parameters, the control force may not be physical or economical to apply.

- Realistic control can be provided by considering time-delay effects.

References:

[1] Adhikari, R. and Yamaguchi, H., 1997, Sliding mode control of buildings with ATMD, Earthquake engineering \& structural dynamics, 26(4), 409-422.

[2] Ozer, H. O., Sayin, A., Korkmaz, N. and Yagiz, N., 2013, Sliding mode control optimized by genetic algorithm for building model, In Proceedings of International Conference on Vibration Problems, 1-10.

[3] Nagashima, I., 2001, Optimal displacement feedback control law for active tuned mass damper, Earthquake engineering \& structural dynamics, 30(8), 1221-1242.

[4] Fitzgerald, B., Basu, B., and Nielsen, S. R., 2013, Active tuned mass dampers for control of in-plane vibrations of wind turbine blades, Structural Control and Health Monitoring, 20(12), 1377-1396.

[5] Aldawod, M., Samali, B., Naghdy, F. and Kwok, K. C., 2001, Active control of along wind response of tall building using a fuzzy controller, Engineering Structures, 23(11), 1512-1522.

[6] Samali, B., Al-Dawod, M., Kwok, K. C. and Naghdy, F., 2004, Active control of cross wind response of 76-story tall building using a fuzzy controller, Journal of engineering mechanics, 130(4), 492-498.

[7] Aly, A. M., 2014, Vibration control of high-rise buildings for wind: a robust passive and active tuned mass damper, Smart Structures and Systems, 13(3), 473-500.

[8] Ahlawat, A. S. and Ramaswamy, A., 2004, Multiobjective optimal fuzzy logic control system for response control of wind-excited tall buildings, Journal of Engineering Mechanics, 130(4), 524-530.

[9] Owji, H. R., Shirazi, A. H. N. and Sarvestani, H. H., 2011, A comparison between a new semi-active tuned mass damper and an active tuned mass damper, Procedia Engineering, 14, 2779-2787.

[10] Guclu, R., and Yazici, H., 2008, Vibration control of a structure with ATMD against earthquake using fuzzy logic controllers, Journal of Sound and Vibration, 318(1-2), 3649.
[11] You, K. P., You, J. Y. and Kim, Y. M., 2014, LQG control of along-wind response of a tall building with an ATMD, Mathematical Problems in Engineering, 2014.

[12] Guclu, R., and Yazici, H., 2009, Seismicvibration mitigation of a nonlinear structural system with an ATMD through a fuzzy PID controller, Nonlinear Dynamics, 58(3), 553.

[13] Sugumar, R., Kajjam, S. and Datta, T. K., 2012, Implementation of active seismic control of a building frame using ANSYS, In International Conference on Engineering, Technology and Management (ICETM Sep'12), 1,1.

[14] Hadi, M. N., \& Arfiadi, Y. (1998). Optimum design of absorber for MDOF structures. Journal of Structural Engineering, 124(11), 1272-1280.

[15] Marano, G. C., Greco, R., \& Chiaia, B. (2010). A comparison between different optimization criteria for tuned mass dampers design. Journal of Sound and Vibration, 329(23), 4880-4890.

[16] M.P. Singh, S. Singh, L.M. Moreschi, Tuned mass dampers for response control of torsional buildings, Earthq. Eng. Struct. D. 31 (2002) 749-769.

[17] Desu, N. B., Deb, S. K., \& Dutta, A. (2006). Coupled tuned mass dampers for control of coupled vibrations in asymmetric buildings. Structural Control and Health Monitoring: The Official Journal of the International Association for Structural Control and Monitoring and of the European Association for the Control of Structures, 13(5), 897-916.

[18] Leung, A. Y. T., \& Zhang, H. (2009). Particle swarm optimization of tuned mass dampers. Engineering Structures, 31(3), 715728.

[19] Leung, A. Y., Zhang, H., Cheng, C. C., \& Lee, Y. Y. (2008). Particle swarm optimization of TMD by non stationary base excitation during earthquake. Earthquake Engineering \& Structural Dynamics, 37(9), 1223-1246.

[20] Bekdaş, G., \& Nigdeli, S. M. (2011). Estimating optimum parameters of tuned mass dampers using harmony search. Engineering Structures, 33(9), 2716-2723.

[21] Bekdaş, G., \& Nigdeli, S. M. (2013). Mass ratio factor for optimum tuned mass damper strategies. International Journal of Mechanical Sciences, 71, 68-84.

[22] Nigdeli, S. M., \& Bekdas, G. (2013). Optimum tuned mass damper design for preventing brittle 
fracture of RC buildings. Smart Structures and Systems, 12(2), 137-155.

[23] Farshidianfar, A., \& Soheili, S. (2013). Ant colony optimization of tuned mass dampers for earthquake oscillations of high-rise structures including soil-structure interaction. Soil Dynamics and Earthquake Engineering, 51, 1422.

[24] Farshidianfar, A., \& Soheili, S. (2013). ABC optimization of TMD parameters for tall buildings with soil structure interaction. Interact. Multiscale Mech, 6(4), 339-356.

[25] Nigdeli, SM \& Bekdaş G. (2015). TeachingLearning-Based Optimization for Estimating Tuned Mass Damper Parameters, 3rd International Conference on Optimization
Techniques in Engineering (OTENG '15), 7-9 November 2015, Rome, Italy.

[26] Nigdeli SM, Bekdas G, Yang XS. Optimum Tuning of Mass Dampers for Seismic Structures Using Flower Pollination Algorithm. 7th European Conference of Civil Engineering (ECCIE '16), 17-19 December 2016, Bern, Switzerland.

[27] Rao, R. (2016). Jaya: A simple and new optimization algorithm for solving constrained and unconstrained optimization problems. International Journal of Industrial Engineering Computations, 7(1), 19-34.

[28] FEMA P-695, Quantification of Building Seismic Performance Factors, Federal Emergency Management Agency, Washington DC, 2009. 